\title{
The Indris Have Got Rhythm! Timing and Pitch Variation of a Primate Song Examined between Sexes and Age Classes
}

\author{
Marco Gamba ${ }^{1 *}$, Valeria Torti ${ }^{1}$, Vittoria Estienne ${ }^{2}$, Rose M. Randrianarison ${ }^{3}$, \\ Daria Valente ${ }^{1}$, Paolo Rovara ${ }^{1}$, Giovanna Bonadonna ${ }^{1}$, Olivier Friard ${ }^{1}$ and \\ Cristina Giacoma ${ }^{1}$
}

${ }^{1}$ Department of Life Sciences and Systems Biology, University of Torino, Torino, Italy, ${ }^{2}$ Department of Primatology, Max Planck Institute for Evolutionary Anthropology, Leipzig, Germany, ${ }^{3}$ Département de Paléontologie et d'Anthropologie Biologique, Faculté des Sciences, Université d'Antananarivo, Antananarivo, Madagascar

A crucial, common feature of speech and music is that they show non-random structures over time. It is an open question which of the other species share rhythmic abilities with humans, but in most cases the lack of knowledge about their behavioral displays prevents further studies. Indris are the only lemurs who sing. They produce loud howling cries that can be heard at several kilometers, in which all members of a group usually sing. We tested whether overlapping and turn-taking during the songs followed a precise pattern by analysing the temporal structure of the individuals' contribution to the song. We found that both dominants (males and females) and non-dominants influenced the onset timing one another. We have found that the dominant male and the dominant female in a group overlapped each other more frequently than they did with the non-dominants. We then focused on the temporal and frequency structure of particular phrases occurring during the song. Our results show that males and females have dimorphic inter-onset intervals during the phrases. Moreover, median frequencies of the unit emitted in the phrases also differ between the sexes, with males showing higher frequencies when compared to females. We have not found an effect of age on the temporal and spectral structure of the phrases. These results indicate that singing in indris has a high behavioral flexibility and varies according to social and individual factors. The flexible spectral structure of the phrases given during the song may underlie perceptual abilities that are relatively unknown in other non-human primates, such as the ability to recognize particular pitch patterns.

Keywords: singing primates, gender differences, lemurs, pitch pattern recognition, musical abilities

\section{INTRODUCTION}

It is an open question whether the human ability to produce and perceive sequences of rhythmic sounds arose in an early or later stage in human evolution. Sequences of rhythmic sounds are the core of the musical melodies we listen to in our everyday life, and there is questioning whether we may find primitive forms of music in other species (Brown, 2000; Geissmann, 2000; Merker, 2000). 
As remarked by Ravignani et al. (2014) temporal properties of animal acoustic behavior should have a primary role in the comparison between human musicality and animal sounds. In animals, there is a wide array of displays that may be welldescribed with the definition of rhythm by McAuley (2010; see also Toussaint, 2013), "the serial pattern of durations marked by a series of events." In animal vocal sequences, these "events" are sounds (units) and silences (silent intervals).

Timing and synchronization play a crucial role in human and animal communication (Bowling et al., 2013; Ravignani et al., 2014). From katydids (Greenfield and Roizen, 1993) to fiddler crabs (Blackwell et al., 2006), to amphibians (Klump and Gerhardt, 1992), the temporal organization of acoustic signals has an important part in mediating interactions between individuals and mate choice. Previous studies have shown that generation of rhythmic sound is common for most apes, as what has been termed as drumming (Schaller, 1963) has been found in chimpanzees (Pan troglodytes, Goodall, 1986; Nishida, 2011; Babiszewska et al., 2015), bonobos (Pan paniscus, de Waal, 1988; Kugler and Savage Rumbaugh, 2002), and gorillas (Gorilla gorilla, Schaller, 1963). These sounds can be produced either by pounding with hands and/or feet on external objects or their body and are common in both captive and wild animals (Arcadi et al., 1998, 2004). However, the ability to produce a rhythmic pattern of acoustic signals does not necessarily correspond to the capacity to coordinate sound production (Fitch, 2013). As suggested by Fitch (2006a,b) and Patel (2008), joint coordination in non-human species appears widespread in sound-mimicking birds (Cacatua galerita, Patel et al., 2009; C. galerita and Psittacus erithacus, Schachner et al., 2009; Melopsittacus undulatus, Hasegawa et al., 2011) and can extend to sea lions (Zalophus californianus, Cook et al., 2013). Studying chorusing dynamics may be of critical importance to understand the flexibility of the individual timing during group displays and the adaptive functions of rhythm (Ravignani et al., 2014). Most studies suggest that monkeys do not perceive a beat and thus they cannot synchronize their movements with it (Macaca mulatta, Zarco et al., 2009; Honing et al., 2012), although a certain degree of behavioral coordination between individuals can found in the chorusing of wild chimpanzees (Fedurek et al., 2013a) and the ability of auditory synchronization has been found in captivity (Hattori et al., 2013). Observations of chimpanzees seeking objects with particular resonant properties and then using them repeatedly to drum also suggested a link between the auditory and motor systems in non-human primates (reported by Fitch, 2012).

Apart from temporal patterns, spectral properties also played a major role in the comparison between human musicality and animal vocal behavior. Previous works focused on the fact that non-human species may have a higher capacity for the temporal processing of sounds and lower sensitivity for the spectral harmonicity (Chinchilla laniger, Shofner and Chaney, 2013; Callithrix jacchus, Pistorio et al., 2006). Studies showed that many non-human primate species, in contrast to humans, did not show considerable differences in average voice pitch between sexes (see Ey et al., 2007 for a review). Patel (2008) suggested that the lack of sex dimorphism in pitch and the limited ability of non-human primates to recognize relative pitch patterns could indicate that sensitivity to pitch changes may be uniquely human, and it may have had had a critical role in the evolution of human musical abilities.

In non-human primates, group calling may have a role in communicating group cohesiveness and in advertising the occupation of a territory (Marler, 2000). Both these functions fit well with the proposed social bonding theory of the evolution of music (Dunbar, 1996) and are crucial for the regulation of territorial ranging patterns and group dynamics (Geissmann, 2002; Gamba, 2014). Non-human primates use song to advertise resource holding potential, to reduce the probability of encounters by regulating group movements in the forest, and to resolve group encounters avoiding physical fights (Mitani, 1985; Cowlishaw, 1996). These findings suggest the existence of neural capacity of advanced sound localization processes in nonhuman primate species producing songs (Brown, 1982; Maeder et al., 2001).

A quantitative, rigorous investigation of non-human primate singing displays may cast new light about the factors affecting individual singing during chorusing. It also may help in identifying the selective pressures that may have led to the evolution of this trait only in Indriidae, Tarsiidae, Callicebinae, Hylobatidae, (Deputte, 1982; Haimoff, 1983; Geissmann, 2000) and may provide insights into the improvement of these abilities during human evolution.

We investigated the rhythmic abilities of a Strepsirrhini species. Strepsirrhines are primates whose last common ancestor with humans is currently dated back between 64 and 87.2 million years ago ${ }^{1}$. There is a single singing lemur species, Indri indri (Gmelin, 1788). The indri lives in the mountain rainforests of Madagascar, where its howling cries can be heard at a distance up to $2 \mathrm{~km}$ (Pollock, 1986). The social organization of indri is based on a reproductive pair where the adult female is dominant over the adult male although the level of intra-group competition is low (Pollock, 1975, 1977). Usually a male, whose relatedness with the adult pair is unknown, is present in the social group, and group size usually varies between two and six animals (Torti et al., 2013). The limited number of adult individuals in a group suggested that intrasexual dominance is age-related (Pollock, 1977, 1979).

The song of the indris is a long sequence of vocal emissions (units) separated by silent gaps and organized in phrases (Figure 1; Thalmann et al., 1993). The indris emit harsh roars at the start of the song, followed by long and scarcely modulated units and, finally, a pattern of descending phrases, which are series of two to six units given with a slightly descending frequency pattern (Thalmann et al., 1993; Sorrentino et al., 2013; Torti et al., 2013). Within the species vocal repertoire, the song is the acoustic display covering the widest range of pitch and all group members aged 2 years and above participate in the song (Maretti et al., 2010). The songs serve to inform neighboring groups about the occupation of a territory and to defend a

\footnotetext{
${ }^{1}$ Strepsirrhines are primates whose last common ancestor with humans is currently dated back between 64 and 87.2 MYA. Estimates may differ according to the methodology used for the phylogenetic reconstruction: 67.1-97.7 MY in Steiper and Young (2006); 64 MY in Chatterjee et al (2009); 87.2 in Perelman et al. (2011).
} 


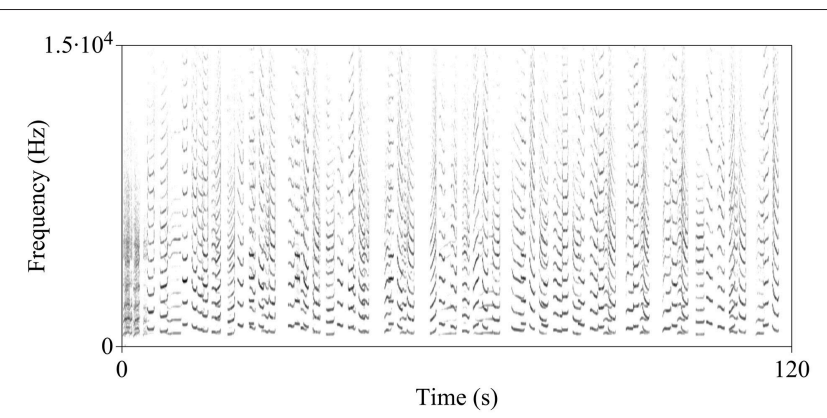

FIGURE 1 | Spectrogram of the indris' song. In this particular song recorded in the Maromizaha Forest, a reproductive pair is singing with a male offspring (Group $1 \mathrm{MZ}$ ).

territory actively during group encounters. They also have a cohesion function (Pollock, 1986; Torti et al., 2013) and are likely to mediate the formation of new groups (Pollock, 1986; Giacoma et al., 2010). It is not clear whether the song may attract partners, but Bonadonna et al. (2014) suggested that, given the scarcity of group encounters, singing may also mediate extra-pair copulation, allow finding a mating partner, and the formation of new groups.

The indri songs are organized behavioral displays where each caller has a precise pattern. Following the frame proposed by Ravignani et al. (2014), we could define the indri songs as the combination of individual aperiodic songs, which shows a complex, uncoupled chorusing of two or more signallers. The calls in the song can be given alternated or simultaneously, with absent, partial, or complete overlap. These characteristics make the indri an excellent model to investigate singing coordination and rhythmic abilities in a non-human species.

Our first aim was to examine coordination during singing between male and female indris. The study of the structure of duetting displays in birds led to two alternative hypotheses. One is that temporal coordination is an honest signal of the coalition quality of the individuals involved (Hall and Magrath, 2007). A coordinated duet is likely to be emitted by an established pair and is more threatening for neighbors than an uncoordinated duet (Brumm and Slater, 2007). A second hypothesis refers to studies demonstrating that temporal coordination may arise when individuals adjust their signals to minimize overlap with conspecifics (Tobias and Seddon, 2009). As the indris form cohesive, territorial pairs, and their songs have a role in advertising territorial occupancy (Torti et al., 2013), we predicted that the reproductive pair would synchronize during singing in most of the songs. Snowdon and Cleveland (1984) showed that pygmy marmosets (Cebuella pygmaea) used calls antiphonally to maintain contact, following an individual-specific pattern and a system of rules. Few studies concentrated on primate turntaking and overlapping during singing. Although a universal pattern cannot be described, studies on members of the family Hylobatidae showed that in sexually dimorphic species, males and females tend to avoid overlapping of their singing, whereas in species where morphological dimorphism is absent singers tend to overlap (Deputte, 1982). From these observations, we predicted that indris, which are not sexually dimorphic and live in socially monogamous groups as gibbons, would overlap during singing. The degree of overlap has been rarely quantified, but the studies of Merker and Cox (1999, Nomascus gabriellae) and Koda et al. (2013, 2014; Hylobates agilis, Hylobates lar) suggested that juvenile gibbons may overlap more often with adults, especially with adult females. Therefore, our prediction is that gender and dominance would affect the singing displays, in particular, nonadult indris overlapping more with the adults comparing to how much the adults overlap each other.

Our second objective was to identify whether the rhythmic structure of the indris differed between sexes and phrases and to show the developmental dynamics of rhythm in indris. Sasahara et al. (2015) demonstrated that rhythm development in birds shows high rates of change during early stages and then slowly refines toward maturity. Our prediction was that the rhythm of the indris' song phrases differed between age classes.

Our third objective was to investigate pitch variation within and between sexes to understand how sex effects on spectral properties of the indri's vocal signals and complement the results on the temporal patterns. We predicted that indris, which are size monomorphic and monochromatic, would lack marked sexual differences in pitch as it has been shown in most of the nonhuman primate species (Ey et al., 2007). Thus, we expect indris not to differ markedly in fundamental frequency between sexes and that pitch patterns presented during the song are analogous akin in both genders.

\section{MATERIALS AND METHODS \\ Study Subjects and Recordings}

We studied 21 groups living in four different areas of dense tropical forest in Madagascar: seven groups in the Analamazaotra Reserve (Andasibe-Mantadia National Park, $18^{\circ} 56^{\prime} \mathrm{S}, 48^{\circ} 25^{\prime}$ E), two groups in Mantadia (Andasibe-Mantadia National Park), three groups in the Mitsinjo Station Forestière $\left(18^{\circ} 56^{\prime} \mathrm{S}, 48^{\circ} 24^{\prime}\right.$ $\mathrm{E})$, and nine groups in the Maromizaha Forest $\left(18^{\circ} 56^{\prime} 49^{\prime \prime} \mathrm{S}\right.$, $\left.48^{\circ} 27^{\prime} 53^{\prime \prime} \mathrm{E}\right)$. We collected data in the field every year between September and December, from 2004 to 2014, for a total of 30 months. We observed one group per day from 06:00 a.m. to 1:00 p.m. Natural marks allowed identifying each indri individually. The reproductive life of indris begins at 6-7 years of age (Pollock, 1977), thus, we labeled all the indris aged six or more as "adults," and all the animals aged between two and five as "non-adults." The reproductive individuals as reported by the guides and the genetic analyses (Bonadonna, unpublished data) were indicated as "dominant," all other members were labeled "non-dominant."

Recordings were made using Sennheiser ME 66 and ME 67 and AKG CK 98 microphones. The microphone output signal was recorded at a sampling rate of $44.1 \mathrm{kHz}$ using a solidstate digital audio recorder (Marantz PMD671, SoundDevices 702, Olympus S100, or Tascam DR-100MKII 24 bit/96 kHz). All utterances were recorded at a distance from 2 to $10 \mathrm{~m}$ since all the study groups were habituated, and all efforts were made to ensure that the microphone was oriented toward the vocalizing animal. All recordings were made without the use of playback stimuli, and nothing was done to modify the behavior of the indris. We 
recorded "advertisement" songs (Torti et al., 2013), consisting of duets and choruses, with a maximum of six individuals singing the same song. When in the field, we had one observer per individual indri in a group. We used Focal animal sampling (Altmann, 1974) that allowed the attribution of each vocalization to a signaller.

We recorded a total of 496 songs. To investigate the coordination during singing, we measured the amount of overlap between two singers of the same group (hereafter, co-singing) and the timing in which each unit started being emitted during a song. For the co-singing analysis, we used 223 songs of 45 individuals (15 dominant adult males, 15 dominant adult females, 15 non-adult indris (11 males, four females). The timing was analyzed in 119 songs and 40 individuals (18 dominant adult males, 14 dominant adult females, three non-adult males, one non-adult female). For the analysis of the rhythmic pattern of the descending phrases (hereafter, DPs), we considered phrases consisting of two (hereafter, DP2), three (DP3), and four (DP4) units extracted from 475 songs and 57 individuals: 23 dominant adult males, 20 dominant adult females, seven non-adult males, three non-adult females. We investigated pitch variation of 1919 DP2s, 2182 DP3s, and 1046 DP4s extracted from 1060 individual song contributions. The sampling included phrases emitted by 25 dominant adult males, 21 dominant adult females, 17 nondominant non-adult indris (10 males and 7 females).

\section{Acoustic Analyses}

We edited segments containing indri's songs using Praat 5.3.46 (Boersma and Weenink, 2008), and we saved each song in a single audio file (in WAV format). Using our field notes and video recordings, we identified and selected the individual contribution of each singer, and we saved this information in a Praat textgrid. We then merged textgrids of all the singers of a song to quantify the co-singing between individuals, and the portions of non-overlapping singing (those in which only one singer was vocalizing). In the case of co-singing of three indris we added that percentage to each dyad involved. We expressed the overall co-singing and non-overlapping as a percentage of the total song duration (Figure 2). The duration of co-singing and non-overlapping segments of each song, as well as the timing of the starting points of each song unit, were saved in Praat and exported to a Microsoft ${ }^{\odot}$ Excel spreadsheet (Gamba and Giacoma, 2007; Gamba et al., 2012). We used the duration of overlapping contributions of each particular pair of individuals to quantify the amount of co-singing between adults and nonadults of both sexes and to calculate the ratio of co-singing within the contribution of an individual to the song. We then used the timing of the starting points of each song unit to understand whether the timing of a singer influenced another indri's song timing. Following Sasahara et al. (2015), we quantified the interonset intervals (IOI) of two adjacent units and used it as a proxy for the rhythmic structure of a phrase.

We processed the DPs to extract the pitch of the focal animal in Praat, discarding the contribution of other singers and the background noise. We analyzed pitch variability by setting a frequency range from the minimum to the maximum of each unit in a DP and then calculating the frequency value at the upper limit of the second (Q50) quartile of energy (Figure 2).

\section{Statistical Analyses}

We ran the General Linear Mixed Models (GLMMs) using the lme4 package (Bates et al., 2015) in R (R Core Team, 2015; version 3.2.0).

The model we used to investigate IOI variation included the duration of IOI as the response variable, IOI type (IOI1, IOI2, or IOI3), sex, age cohort (adult vs. non-adult), and DP type (DP2, DP3, and DP4) as fixed factors and group ID, song ID, site ID, and individual ID as random factors.

To analyse the co-singing, we used a model where the duration of the overlap between two singers was the response variable. The predictors were the duration of the individual contribution, song duration, the number of singers, sex of the focal animal, sex of the co-singer, the status of both the focal animal and the co-singer (identified as dominant or non-dominant in their natal groups). We used group ID, song ID, individual ID (for both the focal and the co-singer), and site ID as random factors. Since, we predicted that the degree of overlap during the song of one individual would be influenced by the sex and the status of its co-singer, we included in this model two interactions: one between the sex of the focal individual and the sex of the co-singer, and another between the status of the focal and the status of the co-singer.

For both models, we verified the assumptions that the residuals were normally distributed and homogeneous by looking at a qqplot and the distribution of the residuals plotted against the fitted values (a function provided by R. Mundry). We excluded the occurrence of collinearity among predictors by examining the variance inflation factors (vif package; Fox and Weisberg, 2011). To test the significance of the full model (Forstmeier and Schielzeth, 2011) we compared it against a null model comprising the random factors exclusively, by using a likelihood ratio test (Anova with argument test "Chisq"; Dobson, 2002). Then, we calculated the $\mathrm{P}$ values for the individual predictors based on likelihood ratio tests between the full and the respective null model by using the R-function "drop1" (Barr et al., 2013). We used a multiple contrast package (multcomp in R) to perform all pairwise comparisons for the levels of each factor with the Tukey test (Bretz et al., 2010). We adjusted all the $p$-values ( $\left.p_{\text {adj }}\right)$ using the Bonferroni correction. We reported estimate, standard error (S.E.), $z$ - and $p$-values for the Tukey tests.

The predictive power of the song unit timing in one individual over another was evaluated using the Granger Casuality test (Granger, 1969). We computed the bivariate Granger causality test in two directions for each dyad of indris singing in a chorus (Brandt et al., 2008; Wessa, 2013) tracking whether they were males, females or non-adults. We used a lag-4 analysis (MSBVAR package v.0.9-1 in R) and considered significant those analyses showing $p$-values below 0.05 (Figure 3). We then calculated the percentage of significant $p$-values on the total of the songs, overall and for each particular dyad. We then average the results per type of dyad. We did not tested dyads of two subadults because of the small sample size.

To analyse the sex dimorphism in pitch, we used four GLMMs where the frequency at the upper limit of the second quartile of 


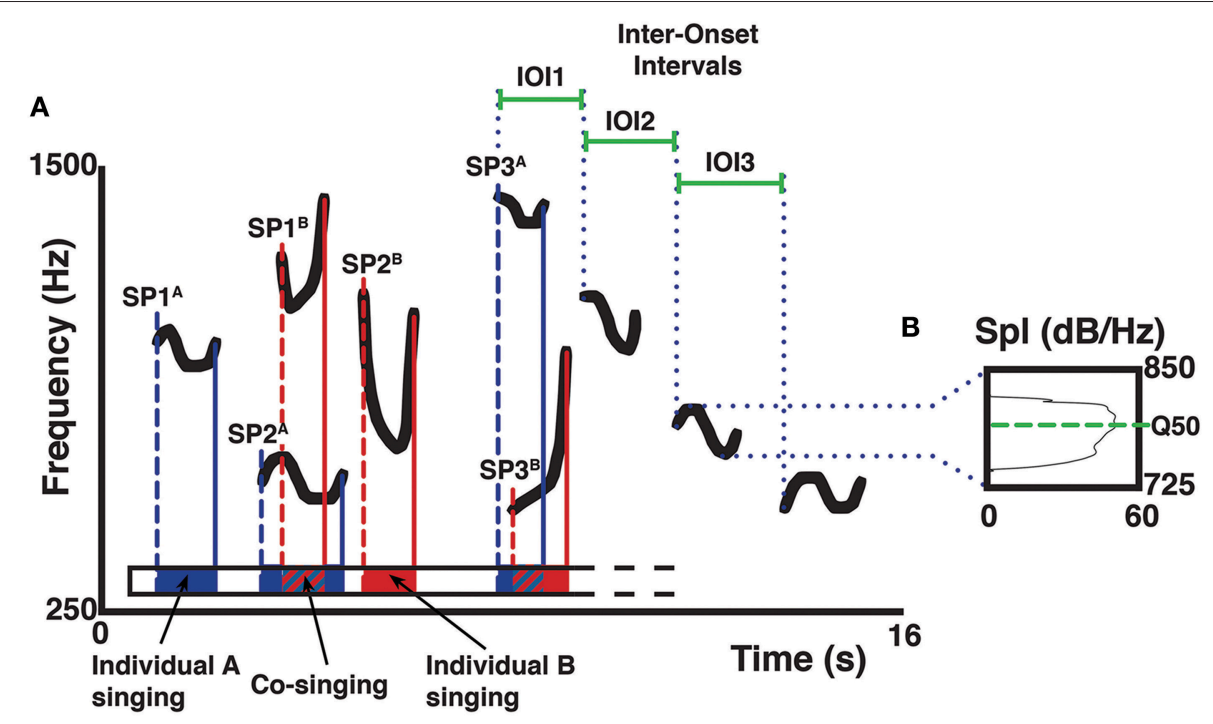

FIGURE 2 | Schematic representation of a spectrogram (A) describing acoustic parameter collection on the isolated pitch of a song. Letters A and B mark different singers, letters SP mark the starting points of a unit $(1,2,3 \ldots)$ in the song. The color bars indicate the starting and final points of the units given by two different indris (e.g., blue for a male; red for a female). Duration of the units is reflected in the schematized Praat textgrid as an interval of the same color, where solid colors indicate non-overlapping parts and striped patterns indicate co-sung portions. Duration of the IOls of a descending phrase is marked by solid green bars. In the spectrum (B) of the third unit (in a descending phrase of four units), the green dotted line marks the frequency corresponding to the upper limit of the second quartile of energy in the spectrum (Q50). The sound spectrum displays sound pressure level (Spl) on the x-axis, frequency on the vertical axis.
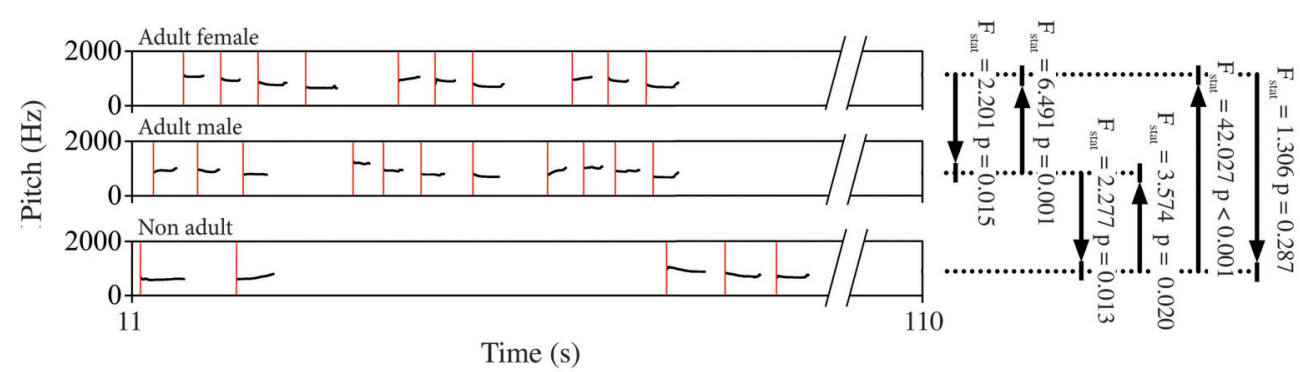

FIGURE 3 | Schematic representation of a spectrogram showing the pitch contour of a portion of the song of three different indris. Red lines mark the starting point of each unit, which were entered in the Granger causality test. Black lines and arrows indicate the dyad and the direction of the test, for which we reported $F$ statistics $\left(F_{\text {stat }}\right)$ and $p$-values $(p)$ as examples.

energy in the spectrum Q50 was the response variable. We run a model for each unit in a DP. The predictors were sex, status (dominant or non-dominant), age cohort (adult vs. non-adult), and DP type (DP2, DP3, and DP4) as fixed factors and group ID, song ID, site ID, and individual ID as random factors. We verified the assumptions and the significance of the models as explained for the models above.

We presented the average variation of IOIs and the average variation of pitch between different units by calculating average individual means, first at the song level, then at the individual level, and finally by sex.

\section{RESULTS}

\section{Overlapping between Singers}

We found a considerable amount of co-singing in all the songs (average individual mean $28.10 \% \pm 7.64, \mathrm{~N}$ individuals $=45$ ).
The average total duration of the song was $113.188 \pm 39.682 \mathrm{~s}$ while the duration of an individual's phonation during the song was $30.132 \pm 10.301 \mathrm{~s}(29.73 \% \pm 11.24)$. The average total cosinging during the song was $8.019 \pm 3.587 \mathrm{~s}$. The full model significantly differed from the null model $\left(\chi^{2}=144.080, d f=9\right.$, $P<0.001)$. Since the interaction between the sexes of the singing pair was not significant, we ran a reduced model excluding such interaction. The results of such reduced model are in Table 1. The duration of co-singing increased significantly with the duration of the individual contribution, but not with song duration itself. The number of singers in a song significantly decreased the amount of co-singing between two singers in a song. Moreover, co-singers' status significantly affected the response variable, with increased co-singing when two non-dominant individuals sang together. We have also found that the two dominant individuals in a group co-sing significantly longer than a dominant and a non-dominant indri (Tuckey test, estimate $=-1.1546$; S.E. 
$\left.=0.2070 ; z=-5.578 ; p_{\text {adj }}<0.001\right)$ and than non-dominants singing together (Tuckey test, estimate $=-1.3719$; S.E. $=0.3598$; $\left.z=-3.813 ; p_{\text {adj }}<0.001\right)$. The model did not detect any effect for the sex of the co-singers.

\section{Gender and Status Influence on the Singing Pattern}

We asked whether singing of a particular indri influenced the contribution of another animal to the song. Applying the causality test between the timing of the onset in the individual contributions, we found an effect of the adult male singing on the pattern of the adult female in $68 \%(N=94)$ of the songs (902.01 $\left.<F_{\text {stat }}<1071.97 ; 0.001<p_{\text {adj }}<0.039\right)$. The timing of the adult female was useful to forecast when the adult male was singing in $73 \%(N=91)$ of the songs $\left(9.53<F_{\text {stat }}<10.44\right.$; $\left.0.001<p_{\text {adj }}<0.043\right)$. The non-adults in a group influenced adult male and adult female singing in $94 \%(N=47 ; 78.20<$ $\left.F_{\text {stat }}<10.08 ; 0.001<p_{\text {adj }}<0.036\right)$ and $75 \%(N=63 ; 9315.05$ $\left.<F_{\text {stat }}<105.22 ; 0.001<p_{\text {adj }}<0.042\right)$ of the songs respectively. We found an effect on non-adults in $81 \%(N=57)$ of the songs for the contribution of the adult female $\left(90.86<F_{\text {stat }}<10.00\right.$; $\left.0.001<p_{\text {adj }}<0.046\right)$ and $78 \%(N=46)$ of the songs for the adult male $\left(9.97<F_{\text {stat }}<10.54 ; 0.001<p_{\text {adj }}<0.030\right)$. We also analyzed data by considering each pair and dyad. We found that non-adults effect on the adult males was $89.10 \% \pm 27.93(\mathrm{~N}=13)$ and all other combinations ranged between $72.31 \% \pm 25.34$ and $76.60 \% \pm 34.42$ (Figure 4).

\section{Rhythmic Differences between Sexes and Age Classes}

We then investigated to what extent sex and age affected indris' singing rhythm. The full model significantly differed from the

TABLE 1 | Influences of the fixed factors on cosinging duration (s); results of the reduced model, including only the significant interaction (full vs. null: chisq $=144.080, d f=9, P<0.001$ ).

\begin{tabular}{|c|c|c|c|c|c|}
\hline & Estimate & $S E$ & $d f$ & $\chi^{2}$ & $P$ \\
\hline (Intercept) & 2.100 & 0.312 & a & a & a \\
\hline $\begin{array}{l}\text { Duration of the individual } \\
\text { contribution }\end{array}$ & 0.018 & 0.002 & 1 & 73.103 & $<0.001$ \\
\hline Song duration & 0.001 & 0.001 & 1 & 1.398 & 0.237 \\
\hline Number of singers & -0.216 & 0.071 & 1 & 8.992 & 0.003 \\
\hline Focal sex (Male) $)^{b, c}$ & -0.029 & 0.154 & 1 & 0.033 & 0.856 \\
\hline Cosinger sex $(\text { Male })^{\mathrm{b}, \mathrm{c}}$ & -0.093 & 0.154 & 1 & 0.335 & 0.563 \\
\hline Focal class (Non-dominant) ${ }^{b, c}$ & -0.840 & 0.187 & d & d & d \\
\hline $\begin{array}{l}\text { Cosinger class } \\
\text { (Non-dominant) }^{b, c}\end{array}$ & -1.138 & 0.184 & $d$ & d & $d$ \\
\hline $\begin{array}{l}\text { Focal class (Non-dominant): } \\
\text { Cosinger class } \\
\text { (Non-dominant) }^{\text {b,c }}\end{array}$ & 0.922 & 0.362 & 1 & 5.955 & 0.015 \\
\hline
\end{tabular}

aNot shown as not having a meaningful interpretation.

${ }^{b}$ Estimate $\pm S E$ refer to the difference of the response between the reported level of this categorical predictor and the reference category of the same predictor.

"These predictors were dummy coded, with the "Focal sex (Female)," "Cosinger sex (Female)," "Focal class (Dominant)," and "Cosinger class (Dominant)" being the reference categories.

${ }^{d}$ Not shown, as the interaction between these predictors is significant. null model $\left(\chi^{2}=144.080, d f=9, P<0.001\right)$. We found that the IOI type significantly affected its duration, in particular both the types IOI2 and IOI3 were significantly longer than IOI1 (Table 2). IOI2 was also significantly shorter than IOI3 (Tuckey test, estimate $=0.063 ;$ S.E. $=0.014 ; \mathrm{z}=44.58 ; p<0.001)$. The IOI duration significantly decreased at the increase of the number of units in the DP (Figure 5; Table 2). In particular, IOIs of DP2s are longer than those in the other DP types, but we found that also IOIs in the DP3s are significantly longer than those in DP4s (Tuckey test, estimate $=-0.179 ;$ S.E. $=0.010 ; z=-17.74 ; p_{\text {adj }}$ $<0.001)$. We have also found a significant effect of sex, where males showed longer IOIs (Table 2) when compared to females. We found no effect of age cohort (Table 2).

\section{Pitch Variation Patterns}

The pitch pattern of the units in a DP showed remarkable interand intra-individual frequency variation (Figure 6). We found that the frequency value corresponding to the second quartile of

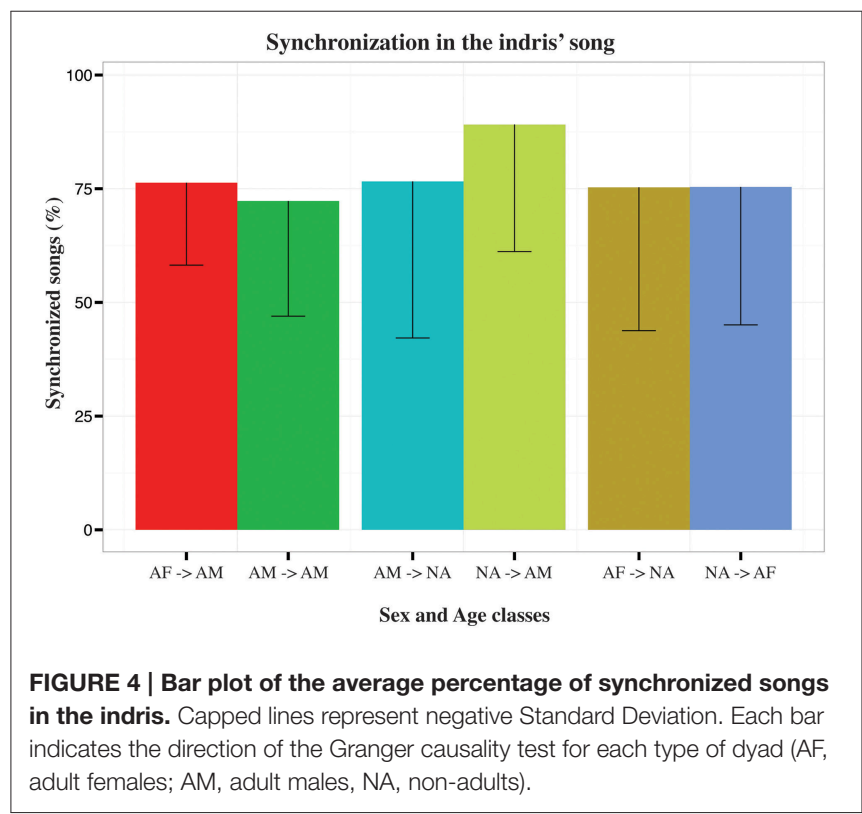

TABLE 2 | Influences of the fixed factors on IOI duration (s); results of the full model (full vs. null: chisq $=2966.748, d f=6, P<0.001$ ).

\begin{tabular}{|c|c|c|c|c|c|}
\hline & Estimate & $S E$ & $d f$ & $\chi^{2}$ & $P$ \\
\hline (Intercept) & 2.094 & 0.049 & a & a & a \\
\hline IOI Type $(2)^{\mathrm{b}, \mathrm{c}}$ & 0.157 & 0.009 & 2 & 2640.061 & $<0.001$ \\
\hline IOI Type $(3)^{\mathrm{b}, \mathrm{c}}$ & 0.785 & 0.014 & 2 & & \\
\hline Sex (Male) $)^{b, c}$ & 0.405 & 0.060 & 1 & 32.848 & $<0.001$ \\
\hline Age Cohort (Not adult) & 0.043 & 0.029 & 1 & 2.152 & 0.142 \\
\hline DP TYPE (DP3), & -0.279 & 0.011 & 2 & 1228.102 & $<0.001$ \\
\hline DP TYPE (DP4) $)^{b, c}$ & -0.458 & 0.013 & & & \\
\hline
\end{tabular}

${ }^{a}$ Not shown as not having a meaningful interpretation.

${ }^{b}$ Estimate $\pm S E$ refer to the difference of the response between the reported level of this categorical predictor and the reference category of the same predictor.

cThese predictors were dummy coded, with the "IOI Type (1)," "Sex (Female)," "Age Cohort (Adult)," and "DP TYPE (DP2)" being the reference categories. 
energy Q50 was significantly higher in males (Table 3) than in females. The Q50 of unit 1 was significantly higher than those of Unit 2, 3, and 4 (Table 3), which appeared descending in the frequency value Q50 along the DP $(-259.485<$ Estimate < -107.059 ; $3.819<$ S.E. $<9.899 ;-39.92<z<-10.81$; all Ps $<$ 0.001). The Q50 also differed significantly between DP types. DP4 and DP3 showed higher values than DP2 (Table 3), and also DP4 showed greater values than DP3 (Tuckey test, estimate $=68.322$; S.E. $=5.264 ; z=12.98 ; p<0.001)$.

\section{DISCUSSION}

\section{Coordination and Overlapping during Singing}

Despite a majority of non-overlapping singing, an important part of the individual song was co-sung with another member

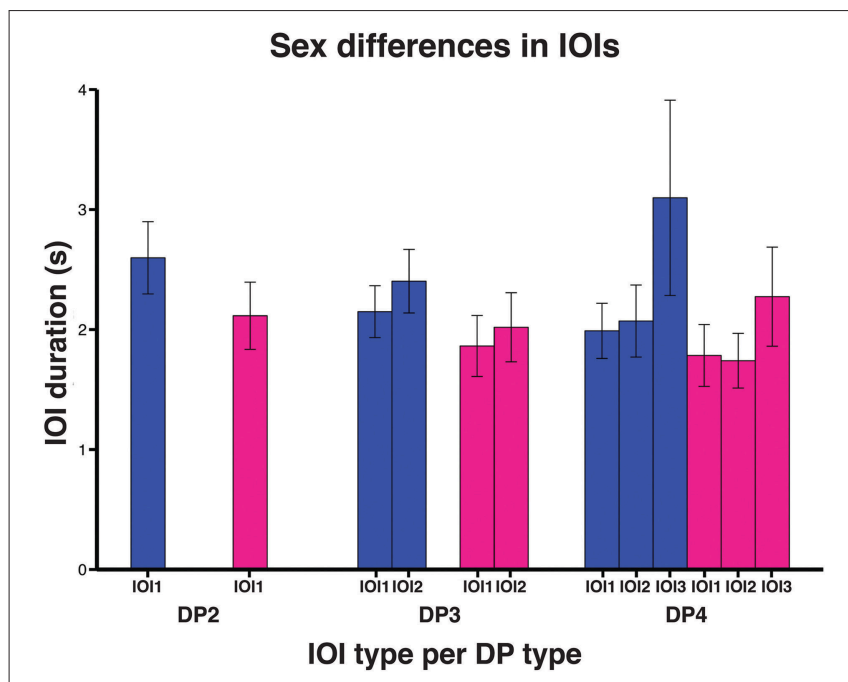

FIGURE 5 | Bar plot of the average IOI duration between DP types in the sexes (males in blue, females in magenta). Capped lines represent \pm Standard Deviation.

TABLE 3 | Influences of the fixed factors on Q50 frequency $(\mathrm{Hz})$; results of the full model (full vs. null: chisq $=4330.685$, $d f=7, P<0.001$ ).

\begin{tabular}{lrrrrr}
\hline & Estimate & SE & $\boldsymbol{d f}$ & $\boldsymbol{\chi}^{\mathbf{2}}$ & $\boldsymbol{P}$ \\
\hline (Intercept) & 967.260 & 13.343 & $\mathrm{a}$ & $\mathrm{a}$ & $\mathrm{a}$ \\
Unit (2) & -104.697 & 2.748 & 3 & 4193.205 & $<0.001$ \\
Unit (3) & -257.122 & 3.819 & & & \\
Unit (4) & -364.181 & 9.780 & & & \\
Sex (Male) & 36.067 & 6.479 & 1 & 21.804 & $<0.001$ \\
Age Cohort (Non-adult) & 9.396 & 6.652 & 1 & 1.984 & 0.159 \\
DP TYPE (DP3) & 33.106 & 2.857 & 2 & 375.086 & $<0.001$ \\
DP TYPE (DP4) & 101.427 & 5.430 & & &
\end{tabular}

aNot shown as not having a meaningful interpretation.

${ }^{b}$ Estimate $\pm S E$ refer to the difference of the response between the reported level of this categorical predictor and the reference category of the same predictor.

"These predictors were dummy coded, with the "Unit (1)," "Sex (Female)," "Age Cohort (Adult)," and "DP TYPE (DP2)" being the reference categories. of the social group with a positive effect of the duration of the singer's contribution rather than overall song duration. We found support for our prediction that indris, being not sexually dimorphic, would overlap during singing, in agreement with what postulated by Deputte (1982) on the Hylobatidae. This finding appears to confirm what previous studies have shown for gibbons. The sex-specific individual song contributions may indeed serve different functions and therefore, may be under different selective pressures (Cowlishaw, 1992; Geissmann, 2002). At the same time, the overlap has an adaptive value because it may have a role in signaling group cohesion and resource holding potential to conspecifics (Torti et al., 2013).

Describing the temporal properties of the indris' singing, we found that the singer's and co-singer's sex did not affect cosinging duration, showing that not only indris of the two sexes participate equally to the song (Giacoma et al., 2010) but they also similarly co-sung with conspecifics of the opposite sex. We found instead that being dominant or non-dominant affected co-singing rates during a group song, in agreement with what Cowlishaw (1992) suggested about the duration of solo bouts in gibbons (see also Mitani, 1984, 1987; Dallmann and Geissmann, 2009). In the indris, solo songs are exceedingly rare. Giacoma and colleagues (unpublished data) recorded three songs emitted

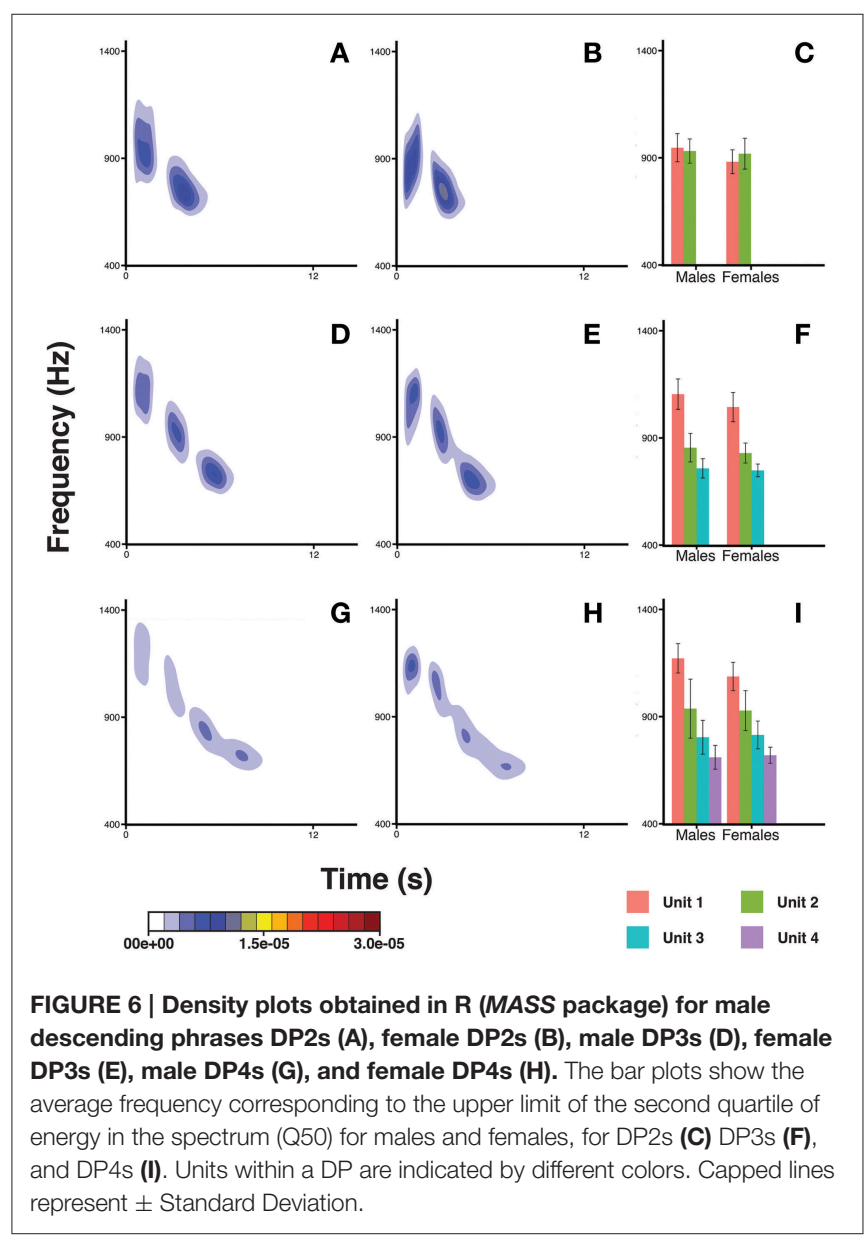


by a single young adult indri male during a sampling time in which over 600 duets and group choruses were recorded. Thus, we can suppose that the indris chorusing may itself play a role in the competition among paired and unmated males, and that conspecifics may assess males' (and females') characteristics from their collective singing (Torti et al., 2013).

The fact that indris showed overlapping avoidance in between dominants and non-dominants (which are often sub-adults in our sampling) and more frequent overlapping between adult males and females marks a difference to what is known for gibbon songs. Adult male gibbons and females tended to alternate their calls and immature individuals frequently overlap (Merker and Cox, 1999; Koda et al., 2013), but a different scenario emerged from our findings. The fact that adults singing together showed a significantly longer overlap falsified our second hypothesis that co-singing rates in these species are higher between nondominants and dominants. Our results suggest that overlap between adults can indeed serve inter-group communication as suggested by previous studies (Merker, 2000). Co-singing may correspond to louder signals, and overlapping of the paired mates may serve to maintain a territory. Non-overlapping singing may provide the advantage of advertising the resource holding potential of the group, but overlapping another conspecific may represent a cost for an individual singer, which cannot broadcast its individuality. It makes sense that non-dominant individuals tend to co-sing less than paired, dominant indris. Non-dominant indris may attempt to maximize their solitary singing during the chorus, to advertise their fighting ability to conspecifics of other groups and their individuality to potential mates (Cowlishaw, 1992).

Studying chorusing dynamics, we found that differences in co-singing reflect differences in coordinating the emissions of units during the song. We demonstrated the existence of a coordination of the calls in both dominant and non-dominant individuals, with a consistent influence between the singing of different indris during the song. We found that the coordination between singers was mutual between sexes and age cohorts, but the non-dominants appeared to have an especially strong effect on dominant adult males. Indris within a group coordinated on average more than $70 \%$ of their songs to form duets, suggesting that duetting is indeed associated with pair cohesion and the strength of the pair bonds (Geissmann and Orgeldinger, 2000). In indris, as it happens for bird species, duetting may have a crucial role in territory defense but may also have evolved for multiple functions (Dahlin and Benedict, 2013), including the localization of conspecific (Torti et al., 2013; Bonadonna et al., 2014) and providing information about the quality of their pair bond (Merker, 2000; Hall and Peters, 2008; Hall, 2009; Dowling and Webster, 2015).

Unlike what Geissmann (2000) hypothesized for gibbons (2000), the indris' song may also facilitate finding a mate either for an extra-pair copulation (Bonadonna et al., 2014) or to form a new pair (Torti et al., 2013). Thus, the interplay between singers can be particularly meaningful for the non-adults which may attempt to broadcast their individuality and may affect the dominant male singing pattern. We cannot exclude that dominant male singing may contribute to the development of singing non-dominant indris, as it has been found in gibbons (Koda et al., 2013).

Acoustic analyses of indris' vocal behavior during the song may also indicate the ability of precise timing in a particular social display, like the song. A parallel with humans may be found in the study of Bowling et al. (2013) showing that speech timing is more precise when speakers are together with a partner than when the same speaker is alone. Further studies are needed, but the investigation of songs given in different behavioral context showed that animals tended to turn taking more precisely when in visual contact than when they were not (Torti et al., 2013). Moreover, dominant adults may indeed have a synchronization capacity that is developing in younger non-dominants.

\section{Rhythmic Differences in the Indris}

We identified a system of distinct units produced in sequences in agreement with previous studies (Thalmann et al., 1993; Giacoma et al., 2010; Baker-Médard et al., 2013; Torti et al., 2013; Gamba et al., 2014). We analyzed short phrases consisting of two, three or four units and we found that the rhythmic structure differed within and between descending phrases. Namely, the interval between onsets decreased significantly during a DP, but also differed between DP types.

These differences in the rhythmic structure of descending phrases suggest that indris may be capable of regulating timing, unit duration, and interval duration. This ability appears similar to those shown by the chimpanzees producing a "pant hoot chorus." In agreement with the findings of Fedurek and colleagues on the chimpanzees, the indris appear to adjust the timing of their emissions (Fedurek et al., 2013a) during the song and to do that to interact vocally with another member of their social group (Mitani and Gros-Louis, 1998). The ability to adjust the emissions within a song has emerged when investigating contextual variation in the acoustic structure of the song (Torti et al., 2013). It may indeed play a role in social interactions within- and between-groups as it has been suggested for chimpanzees' joint hooting (Fedurek et al., 2013b) or agile gibbons' singing (Koda et al., 2013).

We also demonstrated that there is a remarkable difference between males and females, with females showing shorter IOI in all DP types. This sex dimorphism in rhythm is surprising when seen in the light of the indris' social monogamy and external morphology, which would both predict a little dimorphism in the size of the vocal apparatus (Dixson, 2013). Current data on indris' vocal tract morphology is poor, but we found reference to the fact that both males and females possess a dorsal air sac (Grandidier, 1875; Petter et al., 1977). The presence of larger vocal sacs in the male indris could explain the longer IOI observed in all descending phrases. The study on apes showed that there is usually a pronounced sex dimorphism in the size of the vocal sac in the polygynous species (G. gorilla, Pongo pygmaeus), which also produce sex-specific calls (Harcourt et al., 1993; Delgado and Van Schaik, 2000). This dimorphism is apparently less marked in the chimpanzees (P. troglodytes schweinfurthii) group cohesion pant hoots, which are given by both sexes (Mitani and Nishida, 1993). Recent studies on the howler monkeys (Alouatta sp.) confirmed a role of vocal competition and suggested that vocal 
tract traits have been sexually selected in those forest-living, arboreal species (Dunn et al., 2015). Vocal competition can also occur for indris, where sexual monogamy may occur together with the presence of multiple males and females within a group, can involve extra-pair copulation (Torti et al., 2013; Bonadonna et al., 2014) and where inter-sexual selection may have played a role (Singleton et al., 2009).

We found support for our prediction that IOIs differed between males and females. The results instead falsify the hypothesis that rhythm changes during the indris' development because we failed to find clear changes in rhythm between indris of different age cohorts. These results are in disagreement with previous finding on birds (Saar and Mitra, 2008; Sasahara et al., 2015), although the analysis of the entire song instead of single phrases could lead to different results. However, we are convinced that our findings clearly show that non-adults rhythms did not substantially differ from the adult rhythms. These findings also provide insight into the development of the indris' song showing that when the animals start singing the cognitive processes and the vocal apparatus that produces song are fully developed. Thus, the dynamics of the song, at least at a phrase level, has then a limited plasticity.

\section{Pitch Variation}

Our results showed that units emitted sequentially in the DPs differ consistently in frequency, in agreement with the qualitative observations of Thalmann et al. (1993) and Giacoma et al. (2010). The units given during the DPs have a descending frequency on average with remarkable individual variation. We demonstrated that pitch differs between sexes, despite a similar trend in frequency change.

We expected variation within individuals apparently to override sex differences, but the results falsified the prediction that indris lacked marked sexual differences in the pitch of song units. Our findings are in contrast with the general frame reported by Ey et al. (2007) and show that indris present sexual vocal dimorphism. The presence of differences in frequency variation is shown in our study across comparable series of units, and not limited to different unit types, as previously found by Sorrentino et al. (2013).

Indris are sexually monomorphic (Pollock, 1977), and group encounters are rare (Torti et al., 2013). Thus, sex recognition relying on vocal signals is potentially useful and may be indeed encoded both in the rhythmic structure and the frequency of the DP units. The use of song phrases to broadcast sex may be essential during pair formation (Torti et al., 2013) at distances where other communicative signals may be ineffective (Fletcher, 2009).

We support the conclusions of Torti and colleagues suggesting that the song, or part of the song, may be important in sex recognition and for finding mates, but the question of whether indris recognize the sex of an individual listening to its song is still unanswered. As suggested by previous theoretical works, singing in indris is probably the results of several selective pressures that acted differently on the two sexes. Whether indris have a voluntary control over their timing is still unclear and can be further investigated. However, as Gamba (unpublished data) observed in captive siamangs (Symphalangus syndactylus, the emission of harsh sounds ("barks" in siamangs, "roars" in indris) may serve as to synchronize the successive emissions of group members (Giacoma et al., 2010; Torti et al., 2013). Then, the song reaches its most consistent portion of the emission of the descending phrases (Torti et al., 2013), which indeed represent an interesting case of timing and pitch variation, a crucial feature of birdsong and human speech (Levinson and Holler, 2014).

The musical ability of animals has been connected to speciesspecific perceptual templates, which may in some species change according to brain plasticity. However, the extensive evidence of the processes involved in learning concerns bird and humans (Maguire et al., 2000; Kilgard et al., 2001; Anderson et al., 2002) and there is no equivalent evidence for primates. Our knowledge of primates, and especially of "singing primates" is limited to behavioral observations and few experiments. Studies on humans and other mammals demonstrated that learning corresponds to plastic changes in the auditory cortex (Metherlate and Weinberger, 1990; Norton et al., 2005), but it is still unclear whether this can also be the case of non-human primates and can indeed involve processes involved in vocal production learning.

The indris are good candidates for further investigations of the evolution of typical speech features because the turn-taking between individuals, the constant exchange of short vocal units, and the variable degree of overlap are shared trait of modern human communication.

\section{AUTHOR CONTRIBUTIONS}

MG, VT, GB, and CG designed research; MG, VT, VE, RR, DV, GB, and CG performed research; MG, VT, DV, OF, PR, and VE analyzed data; MG, VT, VE, and CG wrote the paper.

\section{ACKNOWLEDGMENTS}

This research was supported by Università degli Studi di Torino and the African, Caribbean, and Pacific (ACP) Science and Technology Programme of the ACP Group of States, with the financial assistance of the European Union, through the Projects BIRD (Biodiversity Integration and Rural Development; No. FED/2009/217077) and SCORE (Supporting Cooperation for Research and Education; Contract No. ACP RPR 118 \# 36) and by grants from the Parco Natura Viva-Centro Tutela Specie Minacciate. We thank Roger Mundry and Colleen Stephens for advice about the GLMMs. We are grateful to GERP (Groupe d'Etudes et des Recherche sur les Primates) and Dr. Jonah Ratsimbazafy. We thank Dr. Cesare Avesani Zaborra and Dr. Caterina Spiezio for helping us with the organization of the field station in Maromizaha. We are grateful to the researchers and the international guides, to Lanto and Mamatin, for their help and logistical support. The contents of this document are the sole responsibility of the authors and can under no circumstances be regarded as reflecting the position of the European Union. We are grateful to two anonymous Reviewers and to the Editor Andrea Ravignani for their comments on a 
previous version of the manuscript. We have received permits for this research, each year, from "Direction des Eaux et Forêts" and "Madagascar National Parks" (formerly ANGAP) [(2004 ( $\mathrm{N}^{\circ}$ 190/MINENV.EF/SG/DGEF/DPB/SCBLF/RECH) 2005 (N 197/ MINENV.EF/SG/DGEF/DPB/SCBLF/RECH), 2006 ( $\mathrm{N}^{\circ}$ 172/06/ MINENV.EF/SG/DGEF/DPB/SCBLF), 2007 ( ${ }^{\circ}$ 0220/07/MINE

\section{REFERENCES}

Altmann, J. (1974). Observational study of behavior: sampling methods. Behaviour 49, 227-267. doi: 10.1163/156853974X00534

Anderson, B. J., Eckburg, P. B., and Relucio, K. I. (2002). Alterations in the thickness of motor cortical subregions after motor skill learning and exercise. Learn. Mem. 9, 1-9. doi: 10.1101/lm.43402

Arcadi, A. C., Robert, D., and Boesch, C. (1998). Buttress drumming by wild chimpanzees: temporal patterning, phrase integration into loud calls, and preliminary evidence for individual distinctiveness. Primates 39, 505-518. doi: 10.1007/BF02557572

Arcadi, A. C., Robert, D., and Mugurusi, F. (2004). A comparison of buttress drumming by male chimpanzees from two populations. Primates $45,135-139$. doi: 10.1007/s10329-003-0070-8

Babiszewska, M., Schel, A. M., Wilke, C., and Slocombe, K. E. (2015). Social, contextual, and individual factors affecting the occurrence and acoustic structure of drumming bouts in wild chimpanzees (Pan troglodytes). Am. J. Phys. Anthropol. 156, 125-134. doi: 10.1002/ajpa.22634

Baker-Médard, M. S. A., Baker, M. C., and Logue, D. M. (2013). Chorus song of the Indri (Indri indri: Primates, Lemuridae): group differences and analysis of within-group vocal interactions. Int. J. Comp. Psychol. 26, 241- 255.

Barr, D. J., Levy, R., Scheepers, C., and Tily, H. J. (2013). Random effects structure for confirmatory hypothesis testing: keep it maximal. J. Mem. Lang. 68, 255-278. doi: 10.1016/j.jml.2012.11.001

Bates, D., Mächler, M., Bolker, B., and Walker, S. (2015). Fitting Linear MixedEffects Models using lme4. J. Stat. Softw. 67, 1-48. doi: 10.18637/jss.v067.i01

Blackwell, P., Jennions, M., Wada, K., Murai, N., and Christy, J. (2006). Synchronous waving in two species of fiddler crabs. Acta Ethol. 9, 22-25. doi: 10.1007/s10211-005-0009-8

Boersma, P., and Weenink, D. (2008). Praat: Doing Phonetics by Computer (Computer Program). Available online at: http://www.praat.org

Bonadonna, G., Torti, V., Randrianarison, R. M., Martinet, N., Gamba, M., and Giacoma, C. (2014). Behavioral correlates of extra-pair copulation in Indri indri. Primates 55, 119-123. doi: 10.1007/s10329-013-0376-0

Bowling, D. L., Herbst, C. T., and Fitch, W. T. (2013). Social origins of rhythm? Synchrony and temporal regularity in human vocalization. PLoS ONE 8:e80402. doi: 10.1371/journal.pone.0080402

Brandt, P. T., Colaresi, M., and Freeman, J. R. (2008). The dynamics of reciprocity, accountability, and credibility. J. Confl. Resolut. 52, 343-374. doi: $10.1177 / 0022002708314221$

Bretz, F., Hothorn, T., and Westfall, P. (2010). Multiple Comparisons Using R. Boca Raton, FL: Chapman \& Hall/CRC Press.

Brown, C. H. (1982). "Auditory localization and primate vocal behavior," in Primate Communication, eds C. T. Snowdon, C. H. Brown, and M. R. Petersen (New York, NY: Cambridge University Press), 144-163.

Brown, S. (2000). "Evolutionary models of music: From sexual selection to group selection," in Perspectives in Ethology: 13. Behavior, Evolution and Culture, eds F. Tonneau and N. S. Thompson (New York, NY: Plenum), 231-281.

Brumm, H., and Slater, P. J. B. (2007). Animal communication: timing counts. Curr. Biol. 17, R521-R523. doi: 10.1016/j.cub.2007.04.053

Chatterjee, H., Ho, S. Y. W., Barnes, I., and Groves, C. (2009). Estimating the phylogeny and divergence times of primates using a super matrix approach. BMC Evol. Biol. 9:259. doi: 10.1186/1471-2148-9-259

Cook, P., Rouse, A., Wilson, M., and Reichmuth, C. A. (2013). California sea lion (Zalophus californianus) can keep the beat: motor entrainment to rhythmic auditory stimuli in a non vocal mimic. J. Comp. Psychol. 127, 412-427. doi: $10.1037 / \mathrm{a} 0032345$

Cowlishaw, G. (1992). Song function in gibbons. Behaviour 121, 131-153. doi: $10.1163 / 156853992 \times 00471$
NV.EF/SG/DGEF/DPSAP/SSE), 2008 ( $\mathrm{N}^{\circ}$ 258/08/MEFT/SG/DG EF/DSAP/SSE), 2009 ( $\mathrm{N}^{\circ}$ 243/09/MEF/SG/DGF/DCB.SAP/SLR SE), $2010\left(\mathrm{~N}^{\circ}\right.$ 118/10/MEF/SG/DGF/DCB.SAP/SCBSE; $\mathrm{N}^{\circ} 293 /$ 10/MEF/SG/DGF/DCB.SAP/SCB), 2011 ( $\mathrm{N}^{\circ}$ 274/11/MEF/SG/D GF/DCB.SAP/SCB), $2012\left(\mathrm{~N}^{\circ}\right.$ 245/12/MEF/SG/DGF/DCB.SAP/ SCB), $2014\left(\mathrm{~N}^{\circ}\right.$ 066/14/MEF/SG/DGF/DCB.SAP/SCB)].

Cowlishaw, G. (1996). Sexual selection and information content in gibbon song bouts. Ethology 102, 272-284. doi: 10.1111/j.1439-0310.1996.tb01125.x

Dahlin, C. R., and Benedict, L. (2013). Angry birds need not apply: a perspective on the flexible form and multifunctionality of avian vocal duets. Ethology 119, 1-10. doi: $10.1111 /$ eth.12182

Dallmann, R., and Geissmann, T. (2009). "Individual and geographical variability in the songs of wild silvery gibbons (Hylobates moloch) on Java, Indonesia," in The Gibbons: New Perspectives on Small Ape Socioecology and Population Biology, eds S. M. Lappan and D. Whittacker (New York, NY: Springer). 91-110.

Delgado, R. A., and Van Schaik, C. P. (2000). The behavioral ecology and conservation of the orangutan (Pongo pygmaeus): a tale of two islands. Evol. Anthropol. 9, 201-218. doi: 10.1002/1520-6505(2000)9:5<201::AIDEVAN2>3.0.CO;2-Y

Deputte, B. L. (1982). "Duetting in male and female songs of the white-cheeked gibbon (Hylobates concolor leucogenys)," in Primate communication, eds S.T. Snowdon, C. H., and M. R. Petersen (Cambridge: Cambridge University Press), $67-93$.

de Waal, F. B. (1988). The communicative repertoire of captive bonobos (Pan paniscus), compared to that of chimpanzees. Behaviour 106, 183-251. doi: $10.1163 / 156853988 \times 00269$

Dixson, A. F. (2013). Male infanticide and primate monogamy. Proc. Natl Acad. Sci. U.S.A. 110, E4937. doi: 10.1073/pnas. 1318645110

Dobson, A. J. (2002). An Introduction to Generalized Linear Models, 2nd Edn. Boca Raton, FL: Chapman and Hall/CRC Press.

Dowling, J., and Webster, M. S.,(2015). An experimental test of duet function in a fairy-wren (Malurus) with moderate cuckoldry rates. Behav. Ecol. 27, 228-236. doi: 10.1093/beheco/arv144

Dunbar, R. (1996). Grooming, Gossip and the Evolution of Language. Cambridge, MA: Harvard University Press.

Dunn, J. C., Halenar, L. B., Davies, T. G., Cristobal-Azkarate, J., Reby, D., Sykes, D., et al. (2015). Evolutionary trade-off between vocal tract and testes dimensions in howler monkeys. Curr. Biol. 25, 2839-2844. doi: 10.1016/j.cub.2015.09.029

Ey, E., Pfefferle, D., and Fischer, J. (2007). Do age-and sex-related variations reliably reflect body size in non-human primate vocalizations? A review. Primates 48 , 253-267. doi: 10.1007/s10329-006-0033-y

Fedurek, P., MacHanda, Z. P., Schel, A. M., and Slocombe, K. E. (2013a). Pant hoot chorusing and social bonds in male chimpanzees. Anim. Behav. 86, 189-196. doi: 10.1016/j.anbehav.2013.05.010

Fedurek, P., Schel, A. M., and Slocombe, K. E. (2013b). The acoustic structure of chimpanzee pant-hooting facilitates chorusing. Behav. Ecol. Sociobiol. 67, 1781-1789. doi: 10.1007/s00265-013-1585-7

Fitch, W. T. (2006a). The biology and evolution of music: a comparative perspective. Cognition 100, 173-215. doi: 10.1016/j.cognition.2005.11.009

Fitch, W. T. (2006b). On the biology and evolution of music. Music Percept. 24, 85-88. doi: 10.1016/j.cognition.2005.11.009

Fitch, W. T. (2012). "The biology and evolution of rhythm: unravelling a paradox," in Language and Music as Cognitive Systems, eds P. Rebuschat, M. Rohmeier, J.A. Hawkins, and I. Cross (Oxford: Oxford University Press), 73-95.

Fitch, W. T. (2013). Rhythmic cognition in humans and animals: distinguishing meter and pulse perception. Front. Syst. Neurosci. 7:68. doi: $10.3389 /$ fnsys.2013.00068

Fletcher, N. H. (2009). The variety of information transfer in animal sonic communication: review from a physics perspective. Entropy 11, 888-906. doi: $10.3390 / \mathrm{e} 11040888$

Forstmeier, W., and Schielzeth, H. (2011). Cryptic multiple hypotheses testing in linear models: overestimated effect sizes and the winner's curse. Behav. Ecol. Sociobiol. 65, 47-55. doi: 10.1007/s00265-010-1038-5

Fox, J., and Weisberg, S. (2011). An R Companion to Applied Regression, 2nd Edn. Thousand Oaks, CA: SAGE Publications, Inc. 
Gamba, M. (2014). Vocal tract-related cues across human and nonhuman signals. Reti Saperi Linguaggi 1, 49-68. doi: 10.12832/77496

Gamba, M., Colombo, C., and Giacoma, C. (2012). Acoustic cues to caller identity in lemurs: a case study. J. Ethol. 30, 191-196. doi: 10.1007/s10164-011-0291-z

Gamba, M., and Giacoma, C. (2007). Quantitative acoustic analysis of the vocal repertoire of the crowned lemur. Ethol. Ecol. Evol. 19, 323-343. doi: $10.1080 / 08927014.2007 .9522555$

Gamba, M., Torti, V., Bonadonna, G., Guzzo, G., and Giacoma, C. (2014). "Overlapping and synchronization in the song of the Indris (Indri indri)," in The Evolution of Language: Proceedings of the 10th International Conference (EvoLangX), eds E. A. Cartmill, S. Roberts, H. Lyn, and H. Cornish (Singapore: World Scientific Publishing). 90-97.

Geissmann, T. (2000). "Gibbon songs and human music from an evolutionary perspective," in The Origins of Music, eds N. Wallin, B. Merker, and S. Brown (Cambridge, MA: MIT Press), 103-123.

Geissmann, T. (2002). Duet-splitting and the evolution of gibbon songs. Biol. Rev. Camb. Philos. Soc. 77, 57-76. doi: 10.1017/S1464793101005826

Geissmann, T., and Orgeldinger, M. (2000). The relationship between duet songs and pair bonds in siamangs, Hylobates syndactylus. Anim. Behav. 60, 805-809. doi: 10.1006/anbe.2000.1540

Giacoma, C., Sorrentino, V., Rabarivola, C., and Gamba, M. (2010). Sex differences in the song of Indri indri. Int. J. Primatol. 31, 539-551. doi: 10.1007/s10764-0109412-8

Gmelin, J. F. (1788). Caroli a Linné Systema Naturae per Regna Tria Naturae, Secundum Classes, Ordines, Genera, Species, cum Characteribus, Differentiis, Synonymis, Locis. Tomus I. Editio Decima Tertia, Aucta, Reformata. Lipsiae: Holmiae.

Goodall, J. (1986). The Chimpanzees of Gombe. Cambridge, MA: Harvard University Press.

Grandidier, A. (1875). Histoire Physique, Naturelle et Politique de Madagascar. Paris: Hachette.

Granger, C. W. J. (1969). Investigating causal relations by econometric models and cross-spectral methods. Econometrica 37, 424-438. doi: 10.2307/1912791

Greenfield, M. D., and Roizen, I. (1993). Katydid synchronous chorusing is an evolutionarily stable outcome of female choice. Nature 364, 618-620. doi: $10.1038 / 364618 \mathrm{a} 0$

Haimoff, E. H. (1983). Gibbon Songs: An Acoustical, Organizational, and Behavioural Analysis. Ph.D. dissertation, University of Cambridge.

Hall, M. L. (2009). A review of vocal duetting in birds. Adv. Stud. Behav. 40, 67-121. doi: 10.1016/S0065-3454(09)40003-2

Hall, M. L., and Magrath, R. D. (2007). Temporal coordination signals coalition quality. Curr. Biol. 17, R406-R407. doi: 10.1016/j.cub.2007.04.022

Hall, M. L., and Peters, A. (2008). Coordination between the sexes for territorial defence in a duetting fairy-wren. Anim. Behav. 76, 65-73. doi: 10.1016/j.anbehav.2008.01.010

Harcourt, A. H., Stewart, K. J., and Hauser, M. (1993). Functions of wild gorilla 'Close' Calls. I. Repertoire, context, and Interspecific comparison. Behaviour 124, 89-122. doi: 10.1163/156853993Х00524

Hasegawa, A., Okanoya, K., Hasegawa, T., and Seki, Y. (2011). Rhythmic synchronization tapping to an audio-visual metronome in budgerigars. Sci. Rep. 1, 120. doi: $10.1038 /$ srep00120

Hattori, Y., Tomonaga, M., and Matsuzawa, T. (2013). The Spontaneous synchronized tapping to an auditory rhythm in a chimpanzee. Sci. Rep. 3:1566. doi: $10.1038 /$ srep01566

Honing, H., Merchant, H., Haden, G. P., Prado, L., and Bartolo, R. (2012). Rhesus monkeys (Macaca mulatta) detect rhythmic groups in music, but not the beat. PLoS ONE 7:e51369. doi: 10.1371/journal.pone.0051369

Kilgard, M. P., Pandya, P. K., Vazquez, J., Gehi, A., Schreiner, C. E., and Merzenich, M. M. (2001). Sensory input directs spatial and temporal plasticity in primary auditory cortex. J. Neurophysiol. 86, 326-338.

Klump, G. M., and Gerhardt, H. C. (1992). "Mechanisms and function of calltiming in male-male interactions in frogs," in Playback and Studies of Animal Communication: Problems and Prospects. NATO Advanced Research Workshop, ed P. MacGregor (New York, NY: Plenum Press), 153-174.

Koda, H., Lemasson, A., Oyakawa, C., Rizaldi, P. J., and Masataka, N. (2013). Possible role of mother-daughter vocal interactions on the development of species-specific song in gibbons. PLOS ONE 8:e71432. doi: 10.1371 /journal.pone.0071432
Koda, H., Oyakawa, C., Kato, A., Shimizu, D., Rizaldi, Koyama, Y., and Hasegawa, S. (2014). Immature male gibbons produce female-specific songs. Primates 55, 13-17. doi: 10.1007/s10329-013-0390-2

Kugler, K., and Savage Rumbaugh, S. (2002). Rhythmic drumming by Kanzi an adult male bonobo (Pan paniscus) at the language research centre. Am. J. Primatol. 57:62.

Levinson, S. C., and Holler, J. (2014). The origin of human multi-modal communication. Philos. Trans. R. Soc. Lond. B Biol. Sci. 369:20130302. doi: 10.1098/rstb.2013.0302

Maeder, P. P., Meuli, R. A., Adriani, M., Bellmann, A., Fornari, E., Thiran, J. P., et al. (2001). Distinct pathways involved in sound recognition and localization, a human fMRI study. Neuroimage 14, 802-816. doi: 10.1006/nimg.2001.0888

Maguire, E. A., Gadian, D. G., Johnsrude, I. S., Good, C. D., Ashburner, J., Frackowiak, R. S., et al. (2000). Navigation-related structural change in the hippocampi of taxi drivers. Proc. Natil. Acad. Sci. U.S.A. 97, 4398-4403. doi: 10.1073/pnas. 070039597

Maretti, G., Sorrentino, V., Finomana, A., Gamba, M., and Giacoma, C. (2010). Not just a pretty song: an overview of the vocal repertoire of Indri indri. J. Anthropol. Sci. $88,151-165$.

Marler, P. (2000). "Origins of music and speech: insights from animals," in The Origins of Music, eds N. Wallin, B. Merker, and S. Brown (Cambridge, MA: MIT Press), 31-48.

McAuley, J. D. (2010). “Tempo and meter," in Music Perception. Springer Handbook of Auditory Research, eds M. R. Jones, R. R. Fay, and A. N. Popper (New York, NY: Springer Science + Business Media), 165-199.

Merker, B. (2000). "Synchronous chorusing and human origins," in The Origins of Music, eds N. Wallin, B. Merker, and S. Brown (Cambridge, MA: MIT Press), 315-327.

Merker, B., and Cox, C. (1999). Development of the female great call in Hylobates gabriellae: a case study. Folia Primatol. 70, 97-106. doi: 10.1159/000021680

Metherlate, R., and Weinberger, N. M. (1990). Cholinergic modulation of responses to single tones produces tone-specific receptive field alterations in cat auditory cortex. Synapse 6, 133-145. doi: 10.1002/syn.890060204

Mitani, J. (1985). Responses of gibbons (Hylobates muelleri) to self, neighbor, and stranger song duets. Int. J. Primatol. 6, 193-200.

Mitani, J. C. (1984). The behavioral regulation of monogamy in gibbons (Hylobates muelleri). Behav. Ecol. Sociobiol. 15, 225-229.

Mitani, J. C. (1987). Territoriality and monogamy among agile gibbons (Hylobates agilis). Behav. Ecol. Sociobiol. 20, 265-269. doi: 10.1007/BF00292179

Mitani, J. C., and Gros-Louis, J. (1998). Chorusing and call convergence in chimpanzees: tests of three hypotheses. Behaviour 135, 1041-1064. doi: $10.1163 / 156853998792913483$

Mitani, J. C., and Nishida, T. (1993). Contexts and social correlates of longdistance calling by male chimpanzees. Anim. Behav. 45, 735-746. doi: 10.1006/anbe.1993.1088

Nishida, T. (2011). Chimpanzees of the Lakeshore: Natural History and Culture at Mahale. Cambridge: Cambridge University Press.

Norton, A., Winner, E., Cronin, K., Overy, K., Lee, D. J., and Schlaug, G. (2005). Are there pre-existing neural, cognitive, or motoric markers for musical ability? Brain Cogn. 59, 124-134. doi: 10.1016/j.bandc.2005.05.009

Patel, A. (2008). Music, Language and the Brain. Oxford: Oxford University Press.

Patel, A. D., Iversen, J. R., Bregman, M. R., and Schulz, I. (2009). Experimental evidence for synchronization to a musical beat in a nonhuman animal. Curr. Biol. 19, 827-830. doi: 10.1016/j.cub.2009.03.038

Perelman, P., Johnson, W. E., Roos, C., Seuánez, H. N., Horvath, J. E., Moreira, M. A., et al. (2011). A molecular phylogeny of living primates. PLoS Genet. 7:e1001342. doi: 10.1371/journal.pgen.1001342

Petter, J. J., Albignac, R., and Rumpler, Y. (1977). Faune de Madagascar, Vol. 44: Mammifères Lémuriens (Primates Prosimiens). Paris: ORSTOM/CNRS.

Pistorio, A. L., Vintch, B., and Wang, X. (2006). Acoustic analysis of vocal development in a New World primate, the common marmoset (Callithrix jacchus). J. Acoust. Soc. Am. 120, 1655-1670. doi: 10.1121/1.2225899

Pollock, J. I. (1975). "Field observations on Indri indri: a preliminary report," in Lemur Biology, eds. I. Tattersall and R. Sussman (New York, NY: Plenum Press), $28-31$.

Pollock, J. I. (1977). "The ecology and sociology of feeding in Indri indri," in Primate Ecology. Feeding and Ranging Behaviour of Lemurs, Monkeys and Apes, ed T. H. Clutton-Brock (London: Academic Press), 37-69. 
Pollock, J. I. (1979). Female dominance in Indri indri. Folia Primatol. 31, 143-164. doi: $10.1159 / 000155877$

Pollock, J. I. (1986). The song of the Indris (Indri indri; Primates: Lemuroidea): natural history, form and function. Int. J. Primatol. 7, 225-267. doi: $10.1007 / \mathrm{BF} 02736391$

R Core Team (2015). R: A Language and Environment for Statistical Computing. Vienna: $\mathrm{R}$ Foundation for Statistical Computing. Available online at: http://www.R-project.org/

Ravignani, A., Bowling, D. L., and Fitch, W. T. (2014). Chorusing, synchrony, and the evolutionary functions of rhythm. Front. Psychol. 5:1118. doi: 10.3389/fpsyg.2014.01118

Saar, S., and Mitra, P. P. (2008). A technique for characterizing the development of rhythms in bird song. PLoS ONE 3:e1461. doi: 10.1371/journal.pone. 0001461

Sasahara, K., Tchernichovski, O., Takahasi, M., Suzuki, K., and Okanoya, K. (2015). A rhythm landscape approach to the developmental dynamics of birdsong. J. $R$. Soc. Interf. 12:20150802. doi: 10.1098/rsif.2015.0802

Schachner, A., Brady, T. F., Pepperberg, I. M., and Hauser, M. D. (2009). Spontaneous motor entrainment to music in multiple vocal mimicking species. Curr. Biol. 19, 831-836. doi: 10.1016/j.cub.2009.03.061

Schaller, G. B. (1963). The Mountain Gorilla: Ecology and Behavior. Chicago, IL: University of Chicago Press.

Shofner, W. P., and Chaney, M. (2013). Processing pitch in a nonhuman mammal (Chinchilla laniger). J. Comp. Psychol. 127, 142. doi: 10.1037/a0029734

Singleton, I., Knott, C. D., Morrogh-Bernard, H. C., Wich, S. A., and Van Schaik, C. P. (2009). "Ranging behavior of orangutan females and social organization," in Orangutans: Geographic Variation in Behavioral Ecology and Conservation, eds S. A. Wich, S. S. Utami Atmoko, T. Mitra Setia, and C. P. Van Schaik (New York, NY: Oxford University Press), 205-214.

Snowdon, C. T., and Cleveland, J. (1984), "Conversations" among pygmy marmosets. Am. J. Primatol. 7, 15-20. doi: 10.1002/ajp.1350070104

Sorrentino, V., Gamba, M., and Giacoma, C. (2013). "A quantitative description of the vocal types emitted in the Indri's song," in Leaping Ahead: Advances in
Prosimian Biology, eds J. Masters, M. Gamba, and F. Génin (New York, NY: Springer Science + Business Media), 315-322.

Steiper, M. E., and Young, N. M. (2006). Primate molecular divergence dates. Mol. Phylogenet. Evol. 41, 384-394. doi: 10.1016/j.ympev.2006.05.021

Thalmann, U., Geissmann, T., Simona, A., and Mutschler, T. (1993). The indris of Anjanaharibe-Sud, northeastern Madagascar. Int. J. Primatol. 14, 357-381. doi: 10.1007/BF02192772

Tobias, J. A., and Seddon, N. (2009). Signal jamming mediates sexual conflict in a duetting bird. Curr. Biol. 19, 577-582. doi: 10.1016/j.cub.2009.02.036

Torti, V., Gamba, M., Rabemananjara, Z. H., and Giacoma, C. (2013). The songs of the indris (Mammalia: Primates: Indridae): contextual variation in the long-distance calls of a lemur. Italian J. Zool. 80, 596-607. doi: $10.1080 / 11250003.2013 .845261$

Toussaint, G. T. (2013). The Geometry of Musical Rhythm. Boca Raton, FL: CRC Press.

Wessa, P. (2013). Bivariate Granger Causality (v1.0.0) in Free Statistics Software (v1.1.23-r7). Office for Research Development and Education, University of Leuven, Leuven.

Zarco, W., Merchant, H., Prado, L., and Mendez, J. C. (2009). Subsecond timing in primates: comparison of interval production between human subjects and rhesus monkeys. J. Neurophysiol. 102, 3191-3202. doi: 10.1152/jn.00066.2009

Conflict of Interest Statement: The authors declare that the research was conducted in the absence of any commercial or financial relationships that could be construed as a potential conflict of interest.

Copyright (C) 2016 Gamba, Torti, Estienne, Randrianarison, Valente, Rovara, Bonadonna, Friard and Giacoma. This is an open-access article distributed under the terms of the Creative Commons Attribution License (CC BY). The use, distribution or reproduction in other forums is permitted, provided the original author(s) or licensor are credited and that the original publication in this journal is cited, in accordance with accepted academic practice. No use, distribution or reproduction is permitted which does not comply with these terms. 